\title{
ReMote Monitoring of PARAMeters for A PRESSURE TRANSDUCER THROUGH HART PROTOCOL AND LABVIEW ENVIRONMENT
}

\author{
RANCEA, I.; SGARCiU , V. \& StAMATESCU, G.
}

Abstract: In this paper we used the concepts of remote control for automated monitoring of parameters for a pressure transducer with sensitive piezorezistive element. The application can monitor the parameters of different industrial processes using the same server. Our case study is using a transducer provided by Siemens - SITRANS P, MS series, 7MF4013 equipped with a HART modem.

Key words: transducer, HART, remote monitoring, LabView
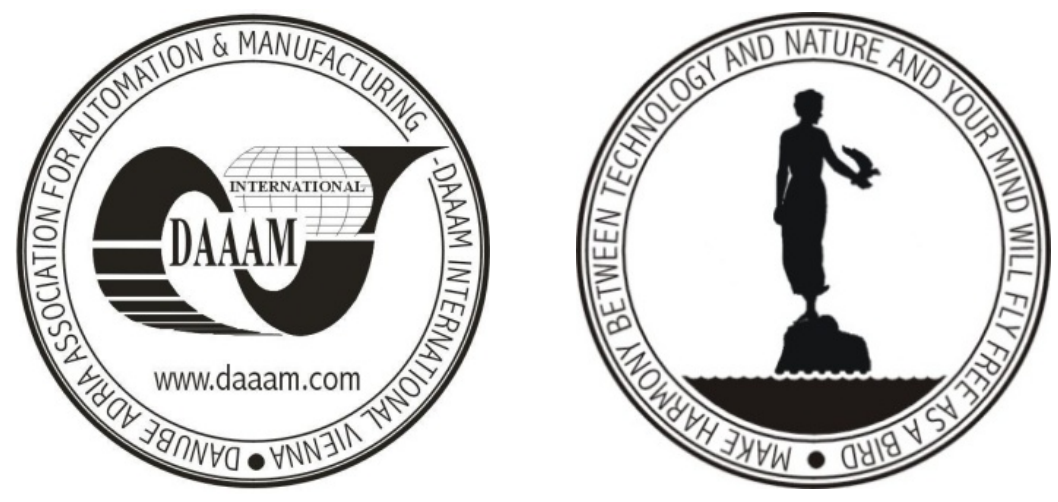

Authors' data: PhD Eng. Rancea, I[rina]; Dr. Prof. Eng. Sgarciu V[alentin]; Eng. Stamatescu G[rigore], The Faculty of Automatic Control and Computers UPB, 313 Splaiul Independentei, Bucharest, Romania, irina.rancea@gmail.com, vsgarciu@aii.pub.ro,grigore.stamatescu@asticontrol.ro

This Publication has to be referred as: Rancea, I[rina]; Sgarciu, V[alentin] \& Stamatescu, G[rigore] (2009). Remote Monitoring of Parameters for a Pressure Transducer through HART Protocol and LabView Environment, Chapter 75 in DAAAM International Scientific Book 2009, pp. 779-786, B. Katalinic (Ed.), Published by DAAAM International, ISBN 978-3-901509-69-8, ISSN 1726-9687, Vienna, Austria DOI: $10.2507 /$ daaam.scibook.2009.75 